\title{
Comment on 'Childhood leukaemia and socioeconomic status in England and Wales 1976-2005: evidence of higher incidence in relatively affluent communities persists over time'
}

\author{
A Smith', T Lightfoot' and E Roman ${ }^{*, 1}$ \\ 'Epidemiology \& Genetics Unit, Department of Health Sciences, University of York, York YO 10 5DD, UK
}

British Journal of Cancer (2012) 107, 217-218. doi:10.1038/bjc.2012.179 www.bjcancer.com

Published online 12 June 2012

(c) 2012 Cancer Research UK

Sir,

Kroll et al (2011) recently reported their findings from an ecological analysis examining paediatric leukaemia registration rates and area-based deprivation in England and Wales. Much to our surprise, selective subgroup findings from the United Kingdom Childhood Cancer Study (www.UKCCS.org) were presented in support of their observations - in our view inappropriately so (Smith et al, 2006). Our comprehensive analysis, published in 2006, stated 'No differences in areabased measures of deprivation were observed between cases and controls at time of diagnosis, either for all cancers combined $(N=4430 ; \mathrm{OR}=1.00,95 \% \mathrm{CI}=0.98-1.01)$ or for acute lymphoblastic leukaemia (ALL) alone $(N=1578, \mathrm{OR}=0.99,95 \% \mathrm{CI}=0.99$, $95 \% \mathrm{CI}=0.96-1.01)$. Findings were similar at time of birth (all cancers $\mathrm{OR}=0.99,95 \% \mathrm{CI}=0.98-1.01)$; (ALL OR $=0.98$, $95 \% \mathrm{CI}=0.96-1.00)$. In addition, no case-control differences were observed when an individual-based measure of SES - social class - based on father's occupation at time of birth was used'. These results were based on all cases diagnosed across the country as a whole and all randomly selected 'first-choice' controls - regardless of whether or not their parents were interviewed in the main study.

Kroll et al (2011) adopted an analytical approach different from ours, concentrating on trend tests and differences between the top and bottom quintile deprivation categories. Leaving aside the merits of the different approaches, our findings and conclusions were not affected by the analytical method used - a fact that is evident from the data presented in our paper. A major strength of the UKCCS is that it can be used to examine the potential impact of various biases - which we discussed at length in our original paper. Given this, we were very surprised to see that instead of quoting from our main results table, as many others have done

\section{REFERENCES}

Adam M, Rebholz CE, Egger M, Zwahlen M, Kuehni CE (2008) Childhood leukaemia and socioeconomic status: what is the evidence? Radiat Prot Dosimetry 132: 246-254

*Correspondence: Professor E Roman, E-mail: eve.roman@york.ac.uk Published online 12 June 2012
(Adam et al, 2008; CRUK, 2011), Kroll et al presented effect measures from the table that excluded the 595 cases whose parents were not interviewed in the main study - despite the fact that we stated that 'the 595 non-interviewed cases tended to live in more-deprived areas'. Clearly, this is the reason why, in our data, the risk estimate for ALL for the most deprived quintile relative to the most affluent in that specific table was 0.76 (0.61-0.95). The odds ratios that should have been quoted are in the table for all 1578 children: 1.0 (reference), 1.10 (0.93-1.30), 0.96 (0.81-1.14), 1.02 (0.86-1.22), and 0.90 (0.97-1.07) for deprivation quintiles 1-5 (Smith et al, 2006). Co-incidentally, within the same edition as the paper by Kroll et al (2011), we presented data from another of our population-based studies that also found no evidence of an association between leukaemia incidence (paediatric and/or adult) and material deprivation (Smith et al, 2011).

In summary, we stand by our original conclusion that the systematic variations with socioeconomic reported in some ecological studies reflect differences in case notification - not differences in underlying disease occurrence (Smith et al, 2006). However, this does not mean that we are unaware of the importance of socioeconomic factors in the disease process. Indeed, using the same UKCCS data set we recently showed that although deprivation is not associated with ALL development, it is related to disease outcome - children in lower deprivation quintiles have significantly higher mortality than those in more affluent groups (Lightfoot et al, 2012).

\section{Conflict of interest}

The authors declare no conflict of interest.
CRUK (2011) Childhood cancer statistics - incidence. Available at: http:// info.cancerresearchuk.org/cancerstats/childhoodcancer/incidence/\#Overall (accessed 5 December 2011).

Kroll ME, Stiller CA, Murphy MFG, Carpenter LM (2011) Childhood leukaemia and socioeconomic status in England and Wales 1976-2005: evidence of higher incidence in relatively affluent communities persists over time. Br J Cancer 105: 1783-1787 
Lightfoot TJ, Johnston WT, Simpson J, Smith A, Ansell P, Crouch S, Roman E, Kinsey SE (2012) Survival from childhood acute lymphoblastic leukaemia: The impact of social inequality in the United Kingdom. Eur $J$ Cancer 48(2): 263-269

Smith A, Howell D, Patmore R, Jack A, Roman E (2011) Incidence of haematological malignancy by sub-type: a report from the
Haematological Malignancy Research Network. $\mathrm{Br} J$ Cancer 105: $1684-1692$

Smith A, Roman E, Simpson J, Ansell P, Fear NT, Eden T (2006) Childhood leukaemia and socioeconomic status: fact or artefact? A report from the United Kingdom childhood cancer study (UKCCS). Int J Epidemiol 35: 1504-1513 